\title{
Mental Health \& Resiliency: Designing Participatory Nature Dependent Environments and Communities for a Sustainable Future
}

\author{
Jacqueline Beam $^{1}$, Nawari O. Nawari ${ }^{1} \&$ Bill Tilson ${ }^{1}$ \\ ${ }^{1}$ School of Architecture, College of Design, Construction, and Planning, University of Florida, USA \\ Correspondence: School of Architecture, College of Design, Construction, and Planning, University of Florida, \\ USA. E-mail: jacquebeam@ufl.edu
}

Received: February 17, 2018

Accepted: March 21, 2018

Online Published: May 30, 2018

doi:10.5539/jsd.v11n3p234

URL: https://doi.org/10.5539/jsd.v11n3p234

\begin{abstract}
Sustainable design trends have historically wended down a road that supports the idea of densely populated urban planning as a strategy for mitigating sprawl. Creation of dense urban areas aims at the reduction of carbon emissions. However, studies show that densely populated areas often come with a panacea of mental health, resiliency, and quality of life ails for a community.

The following research explores the possibility of combining densely populated design approaches with ancient community planning methods that encourage relationship building: close contact with natural environments and social interchange. Community planning that also creates a day to day contact with nature could be a crucial strategy for both sustaining healthy ecosystems and the development of sustainable communities. The potential for integrating dependence upon nature within built urban environments, as well as the possibility of positive place-making by harvesting nature dependent cultural and social assets in communities and neighborhoods, is, therefore, a wealthy area worthy of exploration.

To explore these areas, mental health research on the effects of nature on the brain, as well as the three leading determinants of social, environmental and economic well-being, worldwide, and the founding cultures of these determinants were reviewed. Resilient indigenous groups and case studies of the happiest nation, of Norway and two leading environmentally sustainable and resilient countries, Costa Rica, Cuba, and New Mexico are examined. The paper provides recommendations for improving mental health and resilience by integrating strategies for nature and community needs in urban planning and built environments design.
\end{abstract}

Keywords: biophilia, built environments, community, culture, mental health, nature, participatory, development, place making, sustainable, urban planning, resiliency

\section{Introduction}

Buckminster Fuller believed that nature is executed in perfect design, therefore the model to be mimicked in the design processes of built environments (Buckminster Fuller Institute, 2017). This belief is rooted in the idea that something which has taken billions of years to evolve and adapt to the conditions in which it is dependent, likely has a significant head start on the design process that is unwise to ignore. A relationship of dependency between human beings and nature provides an ever-rewarding opportunity for reciprocal relating and caregiving which are also lessons for survival and stewardship. Much like the relationship between people, the relationship between inhabitants and their environs is also crucial to the health, well-being, and resiliency of both.

There exists a parallel theory of attachment theory in human relating which is the belief that a requirement for healthy relationship development is the act of bonding between the infant and their main caregiver. Originally introduced to the psychology world by John Bowlby, "Attachment theory is a concept in developmental psychology that concerns the importance of "attachment" in regards to personal development. Specifically, it claims that the ability for an individual to form an emotional and physical "attachment" to another person gives a sense of stability and security necessary to take risks, branch out, and grow and develop as a personality" (Psychologist World, 2017).

Further explanations show the correlation between healthy relationship development and the ability to nurture the next generation as a result of actual attachment modeling and bonding in infancy. There are criticisms of the theory, "One of the most common criticisms of attachment theory is that non-Western societies tend to offer up 
compelling counter-examples. For instance, in Papua New Guinea or Uganda, the idea of a child being intimately attached to a caregiver is somewhat alien, and child-rearing duties are more evenly distributed among a broader group of people. Still, "well-adjusted" members of society are produced, indicating that, at least in these societies, some other mechanism is acting in the place of the attachments that are so necessary for Western children" (Psychologist World, 2017).

While the reference to "other mechanisms," is likely the community as a whole, and a broader distribution of caregiving responsibilities, it could also be proposed that one of the "mechanism....acting in the place of the (human) attachment," is that of a relationship developed with nature--an understood and learned dependency on nature. Of relevant note in the quotation above, is that children raised in Papua New Guinea or Uganda, given the open spaces and lack of development prevalent in these countries, experience a greater amount of exposure to nature and a critical dependence upon the immediate environs surrounding them. The idea of the individual's need to bond with nature, not only to provide mental health and increased resiliency capabilities in their lives, yet also, to care for nature itself, poses a question that is of significance to the perceived importance of sustainable practices in society, or the Biophilia Hypothesis (Peter H. Kahn, 1997). Without negating the need for human bonding, biophilia theory suggests that bonding is critical in developing a healthy relationship between human beings and nature. The key aspect of bonding in both attachment theory and the method of biophilia is the connection of relationship and dependence.

If Fuller's theory is correct, and nature is executed in perfect design, the benefits and characteristics shared by individuals who have early contact with nature and are aware of their dependency upon the environment surrounding them, e.g. raised in built environments and communities with the raw materials, water and food harvested from that same nature, should be evident and measurable.

The purpose of this paper is to document the potential correlations between the development of relationship through the built environment: early contact with nature, learned dependence upon nature, participatory community design, and an individual's mental health, resiliency and resulting engagement in environmental stewardship and collaborative community building. Additionally, the research will serve to explore the potential for using this data in the design of participatory sustainable communities; use of natural building materials, living built environments and agro-urban planning.

\section{Goal and Objectives}

The goal of this research is to enrich the mental health and resiliency of communities by emphasizing participatory nature dependent living environments. There are a plethora of reasons why the understanding of the correlation between design and behavior is essential considering the new problems associated with unsustainable human behaviors. The population is increasing while resources and biodiversity are decreasing at alarming rates. Mental health is the single most substantial ill of urban centers with depression and anxiety the most frequent diagnosis, yet science points toward the need for denser pockets of population and protection of the open spaces and resources remaining as an urban planning strategy for mitigating resource usage and carbon emissions (Environmental Protection Agency, 2017). If exposure and interaction with natural environments are critical for the development of a healthy relationship to nature, and mental health stability, there exists a challenge in the construction of urban centers that lack access to the natural world, and an early, learned awareness of humankind's dependence upon ecosystems.

The objectives of this research include studying the normalization of recognition of dependence upon the planet's ecosystems and environmental stewardship engagement to address issues related to mental health stability in urban settings. Moreover, the paper seeks to provide recommendations about enhancing the connections between human psychological behavior and natural systems in urban planning and built environment design.

\section{Literature Review}

Understanding human behavior is critical in the quest for sustainable design as a cultural norm in built environments and lifestyles. Much like biodiversity requires a diverse and complex network of links and systems, the need for the human species as it relates to this biodiverse network is equally complex and layered. Given the prevailing practices of construction and urban planning in the last century and resistance toward stewardship perpetuated by a removed environment in habitat, a result of Cartesian dualism. Mehta (2011) refers to this duality stating, "Mind and body dualism was a convenient philosophy that used the "divide and conquer" strategy to cope with prevalent religious thinking, and subsequently fitted well to deal with the complexity of human nature. It, however, cost us dearly, as it took our focus away from the dynamic nature of human beings, their relationship with the environment and their real health concerns, and to that extent blocked the development of effective 
interventions." The inquiries therefore, worth exploring, are found in, 1) literature and case studies addressing the major influences of environment and culture found on human behavior, 2) sustainably built environment's effect on well-being, resiliency, human behavior in fostering stewardship and, 3) the built environment itself, as a conduit in facilitating the acceptance of sustainability as a norm in construction and regional planning.

The intersection of childhood development and physical health is a widely accepted area of study as are the beneficial effects of green design on health. An area that is less reviewed, which will be the topic of discussion in the following paper, is that of the effects of early nature interaction in a cultural context and the consequences of cultures that place relationship to surroundings and nature-infused, sustainably built environments as a priority in community development and the causal effect on community members' societal behavior and mental health.

The following areas of research will serve to support the theory that human nature and the human need for close contact and dependence upon nature in a collaborative and community-focused manner require consideration in the goal of normalizing sustainable behaviors and stewardship. Further included in the following areas, are qualitative and quantitative research findings from case studies and expert publications in the fields of human behavior, education, sustainability, conservation, built environment, urban planning design, and development.

Biophilia, a term made famous by entomologist and Harvard Professor, Edward Wilson, is best defined as the innate desire that humans possess to connect and experience meaningful ties to nature (Wilson, 1984). The role of place or nature attachment is not to be underestimated. In 2016, PBS featured an award-winning documentary about the power of attachment to one's land, in an extraordinary story titled the "Babushkas of Chernobyl." The true-life stories in the documentary account the journey of grandmothers who returned to their homeland, though forbidden, due to the still high radioactivity levels. Having survived all odds, they are living well beyond the age of their peers who reside outside of the danger zone. Despite the health risks of eating from the contaminated surroundings of medically hazardous radioactivity levels on a day to day basis, these grandmothers fiercely hold on and continue to nurture their land of origin, giving thanks to the very ground, through which they survive, and seemingly thrive (Morris, 2016).

In this story and examples to be reviewed following, the cause of resiliency and evidence of longevity, point in the direction of early bonding with the environment as well as a deep, irrevocable sense of belonging and community ties - invaluable contributors to the increase of mental health. Place attachment is a theory that is paralleled in many ways to the foundations of attachment theory and provides insight into the interrelatedness of cause and effect, and the interpersonal process of connecting in human interaction. The theory is detailed by the author, Bretherton, a research assistant from 1971-1973 for Dr. Mary Ainsworth, the preeminent partner of Bowlby in the development of the attachment theory. In The Origins of Attachment Theory, she states,

"One of the major tenets of security theory is that infants and young children need to develop a secure dependence on parents before launching out into unfamiliar situations." Referencing Salter, Bowlby's wife, Bretherton goes further to describe, "In her dissertation, entitled "An Evaluation of Adjustment Based Upon the Concept of Security," Mary Salter (1940) states it this way: Familial security in the early stages is of a dependent type and forms a basis from which the individual can work out gradually, forming new skills and interests in other fields. Where familial security is lacking, the individual is handicapped by the lack of what might be called a secure base italics added from which to work. (p. 45)" (Altman, 1992)." (Bretherton, 1992).

The premise that secure attachment is born from the development of a consistent and reliable, dependent relationship with another human being is often used in clinical assessments as a measure of one's ability to develop a healthy and interdependent relationship as an adult. Therefore, the same principle and theory might be applied in the measurement of one's ability to create a relationship to nature, using the models of secure attachment requirements; the first of which being first person and consistent contact with nature as well as the maintenance of dependence - or interdependence.

In the writings of The Human Relationship with Nature: Development and Culture, the book reveals that much of the argument of a human being's need for connection and relationship with environment. Kahn(1999) through his extensive case studies on populations throughout the United States, the Amazon, and Portugal, further supports the idea that all human beings seek to connect to life and all living things as a result of encoded evolutionary survival messaging.

Taylor (1988) is an educator who is a strong supporter of the importance of the built environment and of Montessori education. She suggests the following: "human infants and children learn more rapidly in stimulating and varied physical environments which meet basic human needs...The architectural settings can facilitate the transmission of cultural values, stimulate or subdue, aid creativity or slow mental perception, and cause fear or joy...There cannot be separation between the learning process and the physical environment - they are integral 
parts of each other."
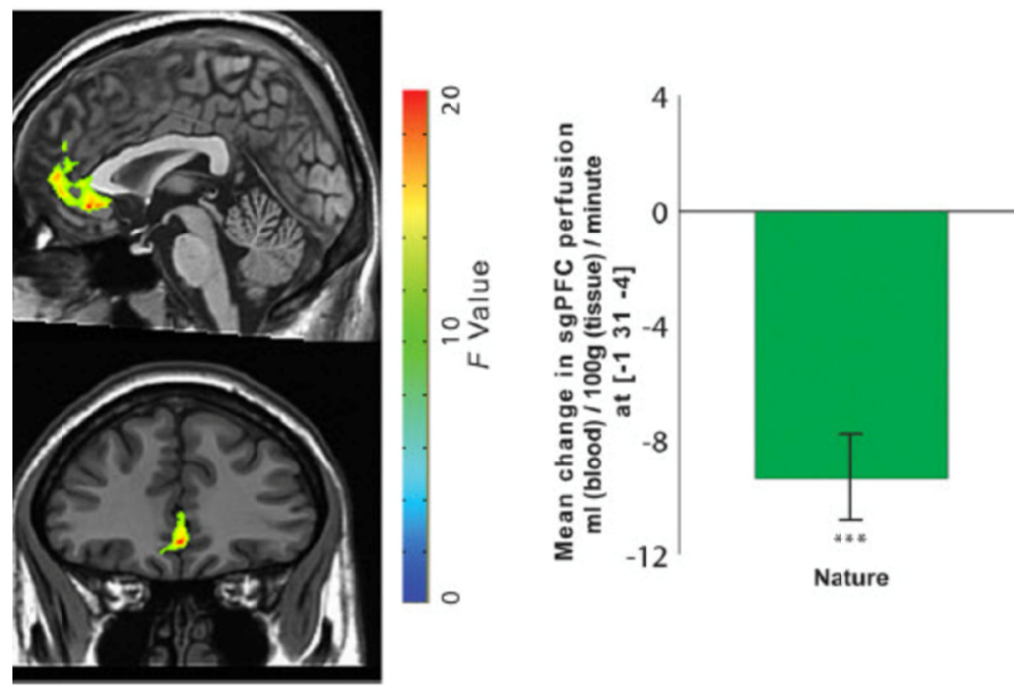

Figure 1. MRI Comparison of brain before and after nature walk in Standford Study of effects of nature on brain, Stanford University, Stanford, California (2017)

In the American Journal of Public Health article, "Healthy Places: Exploring the Evidence," author, Frumkin, (2017) reports on the effects of healthy environments, and the statistics supporting the theory of physical and mental wellbeing as a construct of public health both in urban planning and community development. Chiarotto (2011), a life-long teacher, lists environment as one of the most important resources for teaching children a deeper understanding of the interconnected and interdependent relationships in nature.

What about the measurable science of brain mapping as it relates to relationships with nature? Stanford offers a fascinating study on the effects of a 90-minute walk in nature upon the brain. The study, conducted with 38 participants, compared the MRI results as well as the self-rumination of individuals who walked in nature with those who walked along a busy street in Palo Alto, California (see figure 1). Their findings are unsurprising if one is familiar with the soothing balm of nature. A relative and important reference made in the study points toward the effects of landscapes in the Perceived Restorativeness Scale: "a "soft fascination"; the "sense of belonging"; and the sense of being away." (Bratman, 2015).

"This literature relates to our findings insofar as we may consider these preferred environments to engender the type of positive distraction that has been shown to decrease rumination and negative affect in depressed individuals. Specifically, our findings of decreased sgPFC activity in the nature group point to a possible causal mechanism for the affective benefits of nature experience" (Bratman, 2015).

Considering these findings, imagine the benefits of daily interaction with nature, beyond the mere 90 minutes from which the above study of participant improvements reveal? Further research by Harvard on the effects upon the brain for workers in green buildings which include unobstructed views to green spaces and fresh, outdoor air versus conventional office settings, support the need for moving built environments toward healthier, naturally derived materials and daily contact with interactive nature settings as well.

"They found that cognitive performance scores for the participants who worked in the green+ environments were, on average, double those of participants who worked in conventional environments; scores for those working in green environments were $61 \%$ higher. Measuring nine cognitive function domains, researchers found that the largest improvements occurred in the areas of:

- $\quad$ crisis response (97\% higher scores in green conditions and 131\% higher in green+)

- $\quad$ strategy (183\% and $288 \%$ higher)

- information usage (172\% and 299\% higher)"

(Harvard, 2015).

Yet, absent from these cause and effect links to mental health in the environment is the relationship itself to nature, the interdependent relationship that results when an individual is reliant upon ecosystems in their purer 
form in order to survive, and the relationship that develops as a result. The star assessment and many other measurement tools are widely used by therapists in western mental health, yet, missing in the assessments, that which could provide insight into a much more profound realm of the human psyche, is the address of one's relationship with nature and environment of one's home.

\section{Motivation}

The first step in approach for this research began as a heuristic exploration from the first author's childhood circumstances and observations. Jacqueline Beam grew up rather nomadically, her family moving from one small agricultural town to another throughout Indiana and Ohio. Raised on a farm, her father always maintained a vegetable patch in the back yard. Many of her relatives and friends were farmers or in the livestock or equestrian business, therefore, the author's environments were surrounded by large expanses of fields, peppered by barns, livestock, rivers, lakes and wood thickets. These nature scapes comprised the author's early childhood playgrounds, contributed toward a true sense of belonging, and served as the cornerstones for her lifelong education in survival and coping.

Later, directly out of High School, Beam entered the United States Army: joining the ranks of Military Intelligence, as a French and Spanish linguist. She spent a brief amount of time in Egypt, and Jordan, after which she was assigned to accompany Special Forces missions throughout Panama and Honduras. Frequently required to spend long periods of time in a tent, hunkering down in makeshift shelters from the elements of harsh desert locations outside of Cairo, or the damp, densely vegetated jungle settings of Central America, survival training and skills were not only necessary but an obligatory expectation of her role.

The unusually mobile, nature-full childhood and these trainings came in handy while furthering her adventures as an adult. Returning to the civilian world, she honed her skills dabbling in commercial fishing in the Aleutian islands of Alaska. The author worked as a designer and project manager in the highlands of Guatemala, and remote areas of Costa Rica as well as Peru. She sailed the Caribbean for months at a time while writing about the native culture, ecology and landscape for travel magazines. The last stint of these many years of wandering culminated living in the remote southern region of Costa Rica. It was this experience especially that shaped Beam's views on participatory community design in the Osa Peninsula, while residing and working at a yoga and eco-tourism retreat center on the banks of the ocean. Electricity at the center was generated by solar panels while water was gravity fed from the stream further up the mountain. The walls on the palapa-roofed huts were only three and a half feet high; the rest of the jungle was welcomed in to living areas from the waist up. Beam reports that "of course, there were some nuisances in this arrangement-ants, snakes and spiders chief among them. Bananas were imprisoned in cages while the monkeys schemed and chattered in their attempts to break them free. The laws of nature ruled and those living in the compound were fully aware of the necessities of maintaining the equilibrium within these limits: the dependence upon the water, the sun, the chickens, the garden, the two seasons of hot dry, and warm wet, and the preparations needed for each" (Author, 2017). The author further details that the staff relied heavily upon the wisdom of the locals and the owners, Nikki Luria and Brad Whiteford; an environmentally committed couple who, beginning from tent dwellings, over the course of many years had worked with the land to return it from a deforested cattle pasture to the sustainable paradise it once was.

Reflecting upon this experience, Beam states that "the mental states of staff and locals were not always in perfect hum. However, the ability of most who lived there, to navigate and rise above any feelings of depression and anxiety, or hopelessness, merely in the course of everyday life was undeniably apparent. In hindsight, with the professional lens of a Mental Health Therapist, it is my opinion this ability developed through the healthy relationship scaffolding with natural surroundings and well-forged community ties. There was no avoiding the interdependent relationship with the surrounding nature, its presence always a certainty--demanding our awareness and participation in co-habitation" (Beam, 2017).

Yet, she also expounds upon the observations of visitors who were not bonded with nature: "there were groups that appeared from New York or London, some large metropolis, among whom visitors unequipped for the raw environs of the jungle bubbled to the surface - unlike those of us choosing to live in such an environment, whom did not appreciate the interdependent relationship necessary for survival on the Osa. There was a general consensus among staff and locals residing in the Osa that something was "off" about these folks - something missing in their understanding of the source of life itself, life cycles and their own place within it." The response of the staff to this disconnect was to assist individuals with their coping, all hands were on deck to provide reassurance and support to the frightened and anxiety-ridden - their identified enemy; the unknown environs of raw nature. 
In Last Child in the Woods, author Louv, refers to the one of the founders of the Boy Scouts, Daniel C. Beard, and his books on the experience of youth in nature. "Beard epitomizes a time when a young person's experience of nature was inseparable from the romantic view of the American frontier...But what really defines these books, and the age they represented, is the unquestioned belief that being in nature was about doing something, about direct experience - and about not being a spectator" (Louv, 2005).

The roots of psychology are held in the understanding that the very act of interaction is the foundation of all relationships. This paper proposes that interactions with nature are much the same. In human relationships, the unknown--stranger, culture or ideology is held in fear and contempt, while the intimate and loved ones, known cultures are cherished, preserved, protected and cultivated. Further examination reveals that the ills of the planet have followed a parallel trajectory with the detachment from hands-on processes in nature. An everyday understanding of this trajectory is presented in the current understanding of the rather mundane comparison of fresh produce versus packaged foods: Industrialization and the mechanical overtake of ecosystems are much like packaged foods in the supermarket. It is now widely understood that the majority of packaged food consumers, often lack full understanding of the journey the end product has traversed to arrive on the shelf. Ironically, for the sake of "management," development has likewise veered into a place that leaves the general population equally expectant of the packaged end-product; completely unaware of the processes and steps necessary for the water to run from the tap, the warmth to rise from heaters and the air to chill in refrigerators. This paper further purports that this lack of interactive relationship and awareness leads to misuse of resources and the skill development of basic survival practices. The packaged services which developed nations often take for granted, mask the relevance of survival needs and serve to add to the challenge of a generalized detached relationship to nature.

Following the markers indelibly printed by Beam's formative life descriptions, a comparative, qualitative and quantitative study of case studies was executed: countries and communities that meet the criteria for the topic of this paper are examined in support of the experience and claim. The mental health, resiliency and environmental stewardship qualities of the case studies and populations studied are evidenced through the measurable methods of governmental reports on mental health, resiliency indicators, and environmental resource management. Finally, a combination of approaches are used to culminate the data collection in the text to follow, beginning with an exploratory method to include mental health research on the effects of nature and green built environments on mental health, as well as the three leading determinants of social, environmental and economical well-being, worldwide. Further methods involving descriptive and correlational as well as review methods are used in the study of resilient indigenous groups and case studies of the happiest nation, of Norway and two leading environmentally sustainable and resilient countries, Costa Rica, and Cuba. Regional communities that are practicing sustainable methods near the Santa Fe, New Mexico area, Taos Pueblo and the Greater World Earthship Community, in Taos, as well, are also studied for practical and applicable planning and development solutions in the mid-range populace, high desert city of Santa Fe, New Mexico.

\section{Case Studies}

\section{Macro Perspectives: Reviewing International Case Studies on Happiness, Environmental, Economy Wellbeing \& Resiliency}

In the following case studies of Norway, Costa Rica and Cuba, the three countries differ somewhat in not only their GDP and development levels but their approach to sustainability as well. Yet, one trend in connection is clear - that of the connection between GDP, social welfare, ecological value system and happiness. Undeveloped countries such as Africa rate in the top of the list for environmental well-being and the lowest in happiness and economics, environmental wellbeing cannot therefore be considered a sole determinant of happiness, or mental health, wellbeing and resiliency (Howarth, 2012).

As is indicated in the 17 UN Sustainable Development Goals, and reflected in Maslow's hierarchy of need, it is imperative that the basic needs of a people are met in order for countries to focus upon all of the sustainable development goals, which include education, health and well-being, put forth and recommended by the United Nations. Dissection of the "best of" practices in the following three countries provide a template for developed and developing nations to follow and apply in their own practices and policies. Though the case studies are global and address different cultures and areas of the world, there are also, contained within, valuable practice models that are useful for applications in regional and neighborhood development.

\subsection{Norway}

Norway, the furthest northern European country, resting along the Baltic Sea, is sparsely populated with a little over 5 million in population (Statistics, 2017). As previously mentioned, Norway's high GDP can be attributed 
to oil exports. If happiness is an indicator of mental health, it is important to reflect upon the features that make a country "happy." Norway ranks in the World Happiness Report at number 1 in this regard (Helliwell, 2017).

Though Norway has always ranked high on this particular index, since the first report in 2012, it jumped to number one from fourth place in 2017, a neck to neck race with Denmark, the winning country in prior years. The sudden leap in 2017 has been attributed largely to the country's GDP, yet, oil exports, the source of their high GDP, are carefully managed and limited in amounts. Interestingly, the report finds that children in Norway report the least material deprivation of all countries in the world. In contrast, Norway ranks 119 on the environmental wellbeing scale (Worldwatch, 2017). Though past efforts have not risen to the top of any environmental stewardship listing, the country has made a concerted effort to move toward sustainable goals in more recent years, creating a formal sustainability plan in 2003. The country is also among the highest worldwide in its support and practice of organic farming. Trends reflect decreasing greenhouse gas emissions for Norway throughout the past decade (OECD, 2017). In 2017, the country joined the United Nations in declaring the year for International Sustainable Tourism. Of important note: The culture of practice in the small nation is that all citizens are responsible for the care of the natural resources and ecosystems of the nation. More recent efforts to shift toward a system of measuring and valuing ecosystems, rather than relying wholly on GDP indicators is the direction toward which the government has tacked since 2009 (Disruptive Investor, 2016).

The dramatic beauty of the Norwegian landscape is undeniable; its wild terrain and historical dependence upon fishing reflect a cultural value that is held countrywide. Norwegians are encouraged to engage in the beauty of their land and explore from an early age. The sustainability plan of the nation places the responsibility of stewardship upon its inhabitants emphasizing the dependency that is shared by all upon the environment (Disruptive Investor, 2016).

\subsection{Costa Rica}

As number 12 on the Happiness Report (Helliwell, 2017) and the $26^{\text {th }}$ out of 155 countries in ranking on the environmental wellbeing list, (Worldwatch, 2016) and $93.5 \%$ powered by renewable energy sources, Costa Rica is an excellent example of adaptability and innovation in its use of cultural and environmental service capital. A lush land of verdant jungles and tropical rainforests, the national mantra, "Pura Vida," explains a great deal about the culture in two simple words. The country is unique in its history from much of Central and South America. The small territory has established a history of innovation and investment in education as well as their green economy through incentivizing local communities to care for their regional ecosystems; a government-sponsored payment system (Stiftung, 2013).

Costa Rica has also differentiated itself in its refusal to participate in military pursuits or warfare. That is not to say that this small country has always made the best decisions regarding sustainable practices. In the late 1970's, the health of the land was in great peril. "At the time, forests were being cleared at the rate of 50,000 hectares per year, mostly to enable the production of beef for export to the United States. This represented one of the highest deforestation rates in the world" (Stiftung, 2013). As a response to the devastation, the government-sanctioned parks as protected areas, a move that slowed the deforestation dramatically. Currently, throughout Costa Rica, there are 28 national parks. A total of $27 \%$ of the land mass is under governmental protection.

As a nation that possesses few natural resources in world market demand, the Costa Rican government recognized long before it was popularized, that their biodiversity and tropical Eden-like setting provided the perfect ingredients for eco-tourism. Tourism remains one of the main sources of foreign income and an impetus for the educational concentration amongst its youth, reflected in the land use incentive policies, as well as the designation of protected lands (Stiftung, 2013). Additionally, agricultural exports are the third highest of all exports for Costa Rica pointing toward a direct reliance and dependence upon natural systems in the economy in more areas than just eco-tourism (Central Intelligence Agency, 2017). The area of Nicoya in Costa Rica has recently shone especially in regard to longevity as an identified "Blue Zone," or further described as one of the longevity and happiness islands throughout the world (Buettner, 2010). In an attempt to quantify the phenomenon in terms of environment versus dna, research supports the hypothesis of place attachment and community bonding with findings that those who moved from the area are more likely to experience higher mortality rates than those who remained in Nicoya (Rosero, 2013).

\section{$5.3 \mathrm{Cuba}$}

Cuba offers a sustainable development model that is unique in its foundation as a country that is not only a physical island but also a political island in many ways. Restricted from importing goods and services from the United States since the 1950's, the government was forced to embed sustainable practices into their policies long before sustainability became a popularized term. As a country with a very low GDP, consumption is not 
emphasized in the culture. Instead, like Costa Rica and Norway, the emphasis is placed upon education and health. These two areas are highest on the list of priorities in spending as well as a cultural norm expectation for the Cuban government. The combination of its human-centered focuses has led to a surprisingly high Human Development Index considering their lack of economic strength. Three components comprise the HDI which includes quality of life, education, and economics.

The Worldwide Fund for Nature uses a measurement of sustainable development through measuring ecological footprint, or the biocapacity use of resources per person, as well as the human development index. According to the WWF, "Cuba is the only country that meets these criteria of SD" (Sustainable Development) (Cabello, 2012). In analyzing the status of the small nation, "An approach to sustainable development: The case of Cuba," some of the reasons cited are the closed means of economics, and the Soviet Union collapse. "Cuba transformed itself into a more self-reliant, less energy-intensive society without abandoning its longstanding commitment to robust health and educational programs" (Wiskind, 2007). It is further emphasized in the case study that the placement of people at the center of development objectives accomplishes a, "linking (of) social justice to environmental protection" (Striker, 2010). Striker goes further to explain that due to the human-centered strategy, the potential of individuals is responded to in a qualitative rather than a quantitative manner of approach.

Education is essential in the national goals for Cuba's citizens. The government spends more on education than social security, public health, housing and community services, or the military (Cabello, 2012). UNESCO reports that $99.8 \%$ of citizens over 15 enjoy literacy and as the ages reach 24 , literacy becomes $100 \%$ (2011). Self-sufficiency in energy as well as food, efficiency in the usage of human capacity, are main factors in measuring the solutions for Sustainable Development. Cabello lists the small ecological footprint of Cuba to be in part due to six factors: 1) A wisely constructed environmental policy that allows for accountability, 2) A strategy of energy use that is appropriate given the island's limited resources, 3) A transformed and resilient agricultural system that is adapted to the urban scale, 4) Restrictions on transportation and fuels, 5) Economical planning, 6) Tradition and culture of careful resource usage (2012). Furthermore, the very Constitution of the Republic of Cuba sets forth the basic principle of environmental stewardship in Article 27. "The state protects the environment and the natural resources of the country. The close relation between the economic and the social aspects of sustainable development are acknowledged to make human life more rational and ensure the survival, welfare and security of the current and future generations. The relevant institutions should implement these policies. The citizens must contribute to the protection of water, atmosphere, soil, flora, and fauna and the rich potential of the nature" (Leyes, 1997). Cuba's strategic approach to environmental protection is updated regularly and uses the bio-capacity of areas in order to guide the direction of the living plan.

Though energy consumption is quite low, given the population, what the country is most known for is its success in agriculture. The "need to produce food from the natural, materials and human resources available" (Funes Monzote 2008), is best witnessed in the adaptation of urban agriculture, which has become a way of life with the introduction of "Organipanicos," or local urban farms that provide the necessities in fruits and vegetables the imported rations are not able to fulfill (Cabello, 2011).

\subsection{Commonalities in International Case Studies}

In the three international case studies cited, the following factors are held in common: 1) participatory cultural value system, 2) accountability and responsibility for the environment and for each other, 3) contact with nature from an early age as emphasized in citizen reliance upon agriculture, fishing, and ecotourism, primary education and social welfare, and finally, 4) a high volume of natural, scenic beauty in surroundings. In "Urban Design \& Mental Health" an online journal on urban planning, beauty in surroundings is not to be underestimated in its effect on mental health. In this British study the findings on surveys of inhabitants in scenic environments provide insight into the potential to be found in the beauty of surroundings (Seresinhe, Preis \& Moat, 2015) and (Seresinhe, 2016).

Exploring the potential in "beauty of landscape" factors, in a regional and more intimate manner becomes an important step as well, therefore, toward understanding the efficacy of increasing mental health and resiliency through intentionally designed, sustainable, aesthetically pleasing and scenic, participatory communities. 


\subsection{Regional Case Studies}

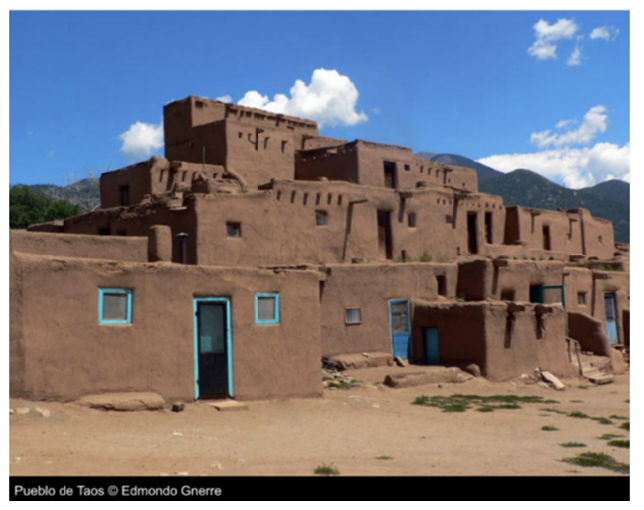

Figure 2. Taos Pueblo, Taos, New Mexico (2017)

Regional case studies on sustainable and participatory community living in the State of New Mexico provide a glimpse of what has worked throughout history as well as effective efforts that are in progress today. The following two areas of Taos Pueblo and the Better World Earthship Community are featured due to their longevity and alignment with the research objectives in design and purpose as outlined in the first few sections of this paper.

\subsubsection{Taos Pueblo}

The Taos Pueblo is a living community of adobe dwellings that has survived since the $13^{\text {th }}$ Century (see figure 2). Situated along the Rio Grande Valley, next to the flowing stream from the Pueblos' sacred Blue Lake and the Rio Grande's abundant tributaries, the adobe structures have been continuously inhabited for 1,000 years. The Pueblo stands as an important symbol for Taos Pueblo Natives who claim their presence in the Valley from the beginning of time (Unesco, 2017).

The structures within the Pueblo compound, are completely sustainable with electricity and piped water forbidden on the grounds. The cultural heritage of the site is revered by the people who choose to live in the ways of their ancestors, hauling water and relying upon the elements to warm and/or cool their homes and gathering spaces. Though some European style doors and windows have been added over the years, their addition is limited and do not take away from the primitive, raw nature of the construction.

Agriculture for the pueblo is centered toward the north of the community not far from the banks of Blue Lake. Red Willow Farm is a collaborative of Indigenous farmers who originate from Taos. Embracing the sustainable potential in modern methods and resources, the land is cooperatively farmed with greenhouses and solar power (Hoover, 2014).

The mental health reports in the Pueblo itself, show less incidence of typical depression and anxiety indicators in comparison to the rest of Taos County and the State of New Mexico, according to City-Data (2017). The information collected by City-Data demonstrates a possible correlation between environmental, social well-being and increased mental health and coping, rather than causality. Furthermore, given the circumstances of poverty level income and years of oppression experienced by native populations, Taos Pueblo included; it is difficult to ascertain the direct cause of increased resiliency and mental health in this community. However, the residents of Taos Pueblo, in their rich community and cultural connection, required engagement in the ecosystems of their environment and relationship to nature, certainly provide an area for further study that reflects the potential of a controlled study to explore a deeper understanding of the City-Data's findings. 


\subsubsection{Earthship Community, Taos}

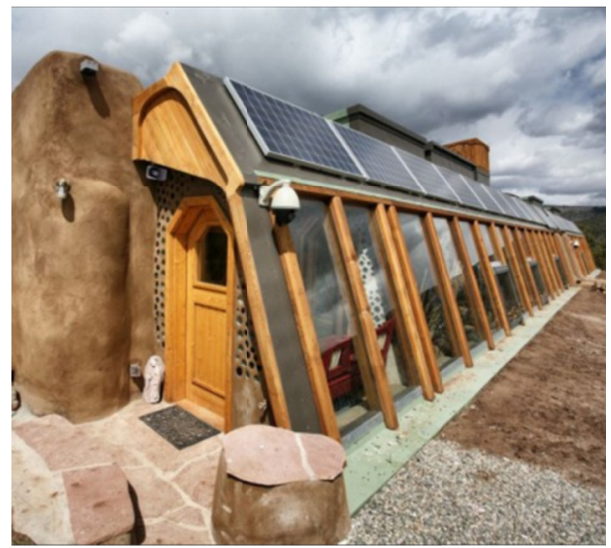

Figure 3. Earthship dwelling, Greater World Community, Taos, New Mexico (2017)

The Greater World Earthship Community also located in Taos, is comprised of buildings made of earth and recycled materials, completely off grid, with built in green houses that serve to provide readily accessible food, passive solar warmth directed toward the interior walls, and recycling of gray and black water in vegetation growing tanks as well. The rammed earth, semi-buried dwelling design is highly self-sufficient, and requires inhabitant engagement and maintenance for meeting most survival needs (see figure 3 and 4). A vision of architect Michael Reynolds, beyond LEED, these buildings are representative of the closest, non-indigenous example to the living building challenge achievable (Earthship Biotecture; Design Principles, 2017).

Featured in the Sustainable [Revolution] Project website and book by Juliana Birnbaum \& Louis Fox (2014), the earth dwellings are a tried and true product with a lower price point intentioned for accessibility to the masses. According to Reynolds, the Global Model design, in particular, can be used in any urban setting as well as rural, in challenging, geographical locations throughout the world (Earthship Biotecture, 2017). The structures feature: Recycled tires lining back wall and two sides for structure, earth berm construction for insulation, south facing orientation, adobe bricks and/or rammed earth walls for optimum solar gain, rooftop rain harvesting, gray water recycling $4 \mathrm{x}$, blackwater biodigestion, and an attached greenhouse which also serves a passive solar/natural humidifier function.

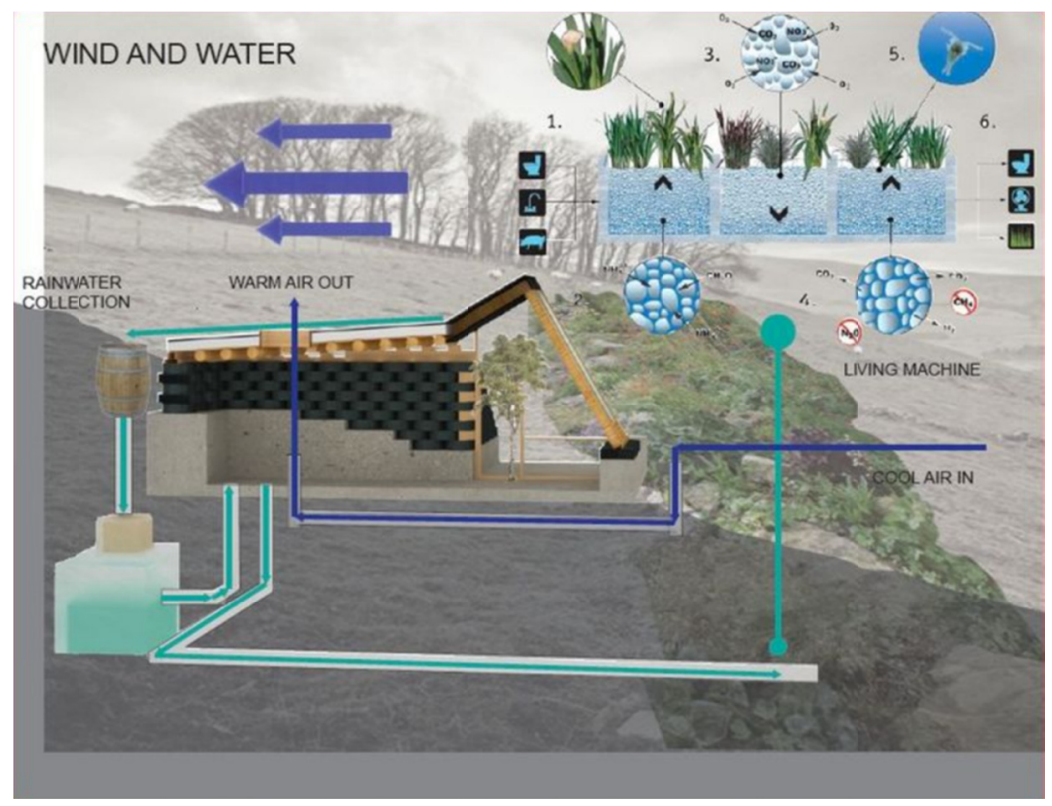

Figure 4. Earthship structure ecosystems design drawing (2017) 
Inhabitants of earthships are required to monitor the functions of the structure from water collection to energy collection and use on a daily basis. A collaborative community cultural value is relied upon within this community for filling in the gaps when needed through an exchange of goods and services amongst community members. Though measurement of mental health in the Greater World subdivision is not available in public records or reports, interestingly enough, the small community with only 200 habitants, has the lowest crime rate of Taos County according to the Real Estate organization of Trulia (2017). Crime rates are considered to be an indicator of community mental health. Much like the strategies of Costa Rica in spreading awareness and focusing upon eco tourism and sustainability education, green building tourism and educational workshops have become a major source of income for the Greater World community.

\section{Recommendations: Follow Nature and Community Needs in Urban Planning and Built Environments}

Considering the indicators of positive mental health, and resiliency as well as the potential of direct contact with nature and interactive relationships with nature as a vital factor in the increase of mental health and resiliency, it is recommended that built environments and urban planning incorporate the requirement for nature interaction in the planning process as well as design, to include retrofitting for increased interaction and dependence (Lejuwaan, 2012).

Common denominators found in Costa Rica and Cuba, highly resilient countries, and Norway, a very happy country, are in the natural beauty of the land and intimate relationship with natural systems as well as prioritization of economic investment in education and human capital. As a country, the synthesis of both, resilience and happiness, are found mostly in Costa Rica. Through its culture, practice, and adaptive policies that require a recognition of dependence with the laws of nature and ecosystems in a direct, culturally and economically valued manner, Costa Rica stands out as a true leader. This recognition follows a chain of infrastructure from the national governing bodies to the local governing bodies-attachment to nature and an interdependent relationship to nature is part of the very fabric of their culture and value system.

Regionally, much is to be learned from both the Taos Pueblo and The Greater World Community. While it is not feasible to build earth structures in a large-scale manner within urban centers, many of the retrofitting strategies found in Reynold's Earthship Biotecture plans can be used for reducing energy and water usage while maximizing water harvesting opportunities and creating closer end-point, agricultural resources. The power of neighborhoods to spontaneously form in beehive clusters of industry around a green space and collectively strategize for water harvesting, passive solar construction additions, and food sourcing is relatively untapped. This collective formation of resilient and self-sufficient neighborhoods within cities and regions has the potential to change the landscape to that of tried and true ecological practices of indigenous and rural communities of the past: the idea of which brings to mind barn raising, community harvests, and collective water management such as the effective ancient acequia system.

The Robert Wood Johnson Foundation reports a number of initiatives in the revitalization of neighborhoods which serve to support economic development as well as increase physical and social well-being providing the "appropriate scale, wholeness and connectedness...The U.S. Public Health Service Task Force on Community Preventive Services and a team of experts have recognized the large potential health impact of such initiatives" (Robert Wood Johnson Foundation, 2008). Some of the most important steps the commission recommends are found in 1) engaging the community in organizing collectively to work with each other for improvement actualization, 2) following the principles of "environmental justice" in interventions by ridding health hazards as well as ensuring services are provided equally in all locations throughout a city. Socially, approaches are encouraged which address residential segregation and work to eliminate the lines that keep communities separated and the expansion of accessible housing in areas that offer employment and top quality schools (Robert Wood Johnson Foundation, 2008).

The development style of urban areas and communities since the industrial age and especially so, since the 1950's, has moved toward the suburban model, a segregated commercial and living design that often requires long commutes to reach a job location, or shop at a grocery store. Prior to this time period, communities were designed in clusters or

"barrios," closer in proximity to the day to day needs of life and community gathering spaces as well as economy of commerce which were integrated within the community layout (Herzog, 2006). Returning to these concepts is possible with small segments of areas in an urban setting transforming sprawl into a neighborhood, or pocket neighborhood. Creation of pocket neighborhoods provide the community connection needed in the often experienced disconnection to place that those who live in the suburbs feel. The Aut-Aut Nursery Site Plan shown in Figure 5 provides in its design for children's learning experiences, a number of neighborhood features listed in 
the Commission on Health, that can be applied to neighborhoods, as well as the essential interaction with nature in day-to-day activities - the practice of interdependent nature and human relationships in action (Anzilotti, 2016).

Keeping in mind the pocket neighborhood concept, it would behoove cities to identify areas within limit boundaries that might be amenable to retrofitting for sustainability and the clustering, integrated strategies of mixed-use neighborhoods. Small steps should be incorporated within a neighborhood as well, in order to create daily contact with ecosystems and a deeper understanding of the many ways nature provides for the survival needs of a population. Water management is a major concern in densely populated areas. Some simple techniques incorporated into the landscape, such as rain gardens, bioswales, and rain barrels, for instance, with educational signage would provide a more intimate contact with these systems, and therefore, set the stage for increasing awareness of humans' interdependent relationship.

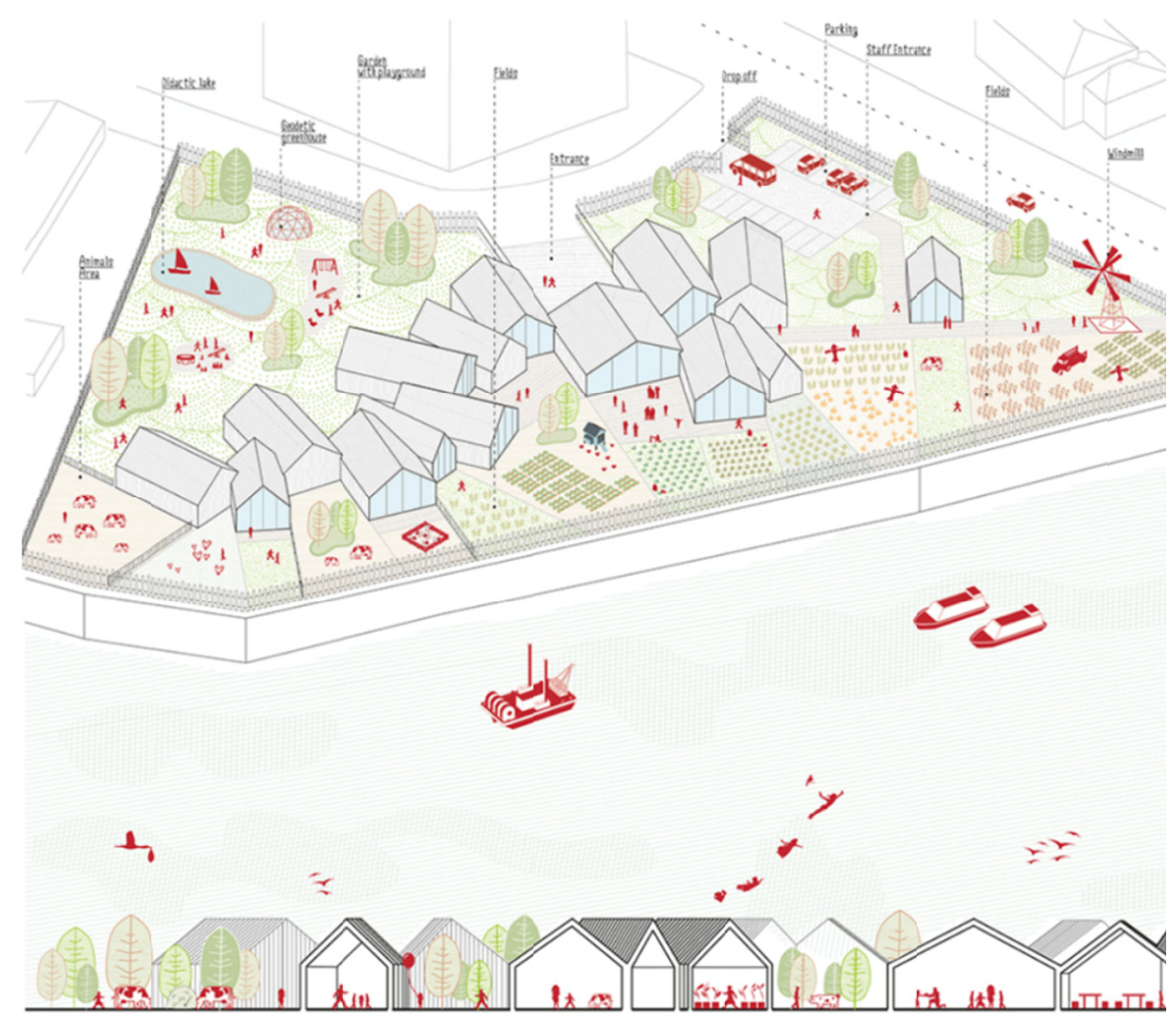

Figure 5. Aut-Aut Nursery Fields Forever Site Plan, 2015; London-First Prize AWR Competitions (2017)

Given the difficulty and expense, not to mention the loss of historical relevance, in razing a location to create a "sustainable" habitat or community, a logical next step is to explore the concept of neighborhood retrofitting, and cultural asset harvesting. Due to its long-standing history of value for the vernacular structure as well as the rich cultural context in water management and agriculture, Santa Fe, New Mexico presents an exceptional stage for the application of this paper's hypothesis in real time.

\subsection{Cultural Context in Planning: Santa Fe, New Mexico-Water, Agriculture, the Pueblo \& The Plaza}

Originally inhabited by a number of agricultural Native American groups and eventually taken over by Spanish settlers in 1607, as in many such settlements, the central feature and draw for the indigenous pueblos and the establishments to follow in the Santa Fe region, was the Santa Fe River, mountainous protection, resources, and rich, alluvium valley planting areas. The cultures which endured prior to industrialization, hold a vast library of knowledge; The Native American communities throughout the Southwest are cultures which provide excellent regional examples of enduring biophilic tradition and longevity. As with many religions of the Pueblo Indigenous, life, religious beliefs and culture are inseparable. The harmonious connection with nature is an ideal to be strived for in every action and way of life. Balance within society is defined through reciprocal relationships, "within which people connect and harmonize with each other, the natural world, and time itself" (what-when-how; Nambe Pueblo (Native Americans of the Southwest, 2017). 


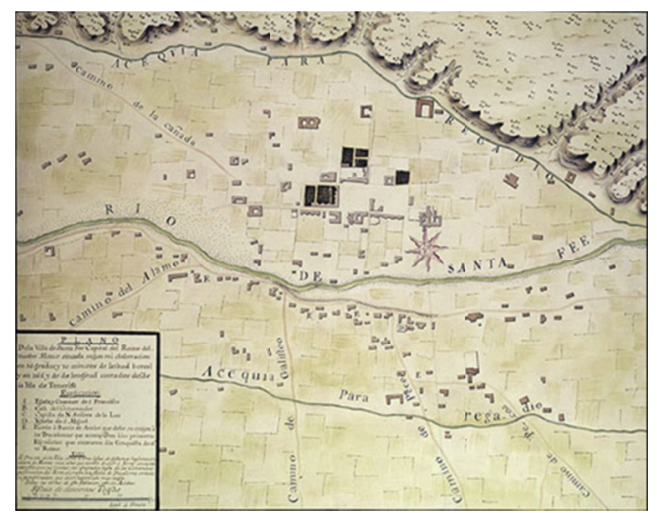

Figure 6. Original site plan map of Santa Fe, New Mexico Central Plaza (2017)

In consideration of the importance of nature's elements in day to day Pueblo life, as demonstrated in the aforementioned Taos Pueblo, the center of activity, along with dwellings, were and continue to be in those still existing today, clustered in a manner that promotes these value systems. The orientation of structures is strategically placed with agricultural fields and nature surrounding. Interconnected habitats and centralized gathering spaces for the community dominate in the center, the nucleus from which all social and community needs, as well as daily exchanges are carried out.

The establishment of Santa Fe, following the Spanish Colonial tradition of community planning in Figure 6, like the Pueblos, also centered life not only near the water source of the Santa Fe River, yet also around a focal gathering point, or the plaza (Herzog, 2006). However, unlike the wise choices of early community planning, sprawl has become the more recent norm in Santa Fe as well as cities throughout the world. Unfortunately, the overhaul of rebuilding communities from scratch in order for inhabitants to experience a more intimate connection to nature in day to day life is an undertaking that would require a great deal of financial outlay; the action of which is not the most sustainable solution for solving the challenge. Rather than new construction, the Ecovillage of Ithaca, a community that has cohabitated as a collaborative community since the early 90 's in a similar pattern as has been described throughout this paper, recommends taking small steps in transformation toward greener living. The community suggests that equality in voice, partnership with neighbors and incrementally moving towards more sustainable methods, both structurally and in habits of practice comprise the most successful model for creating longevity and effectiveness in sustainability (Ecovillage Ithaca, 2017).

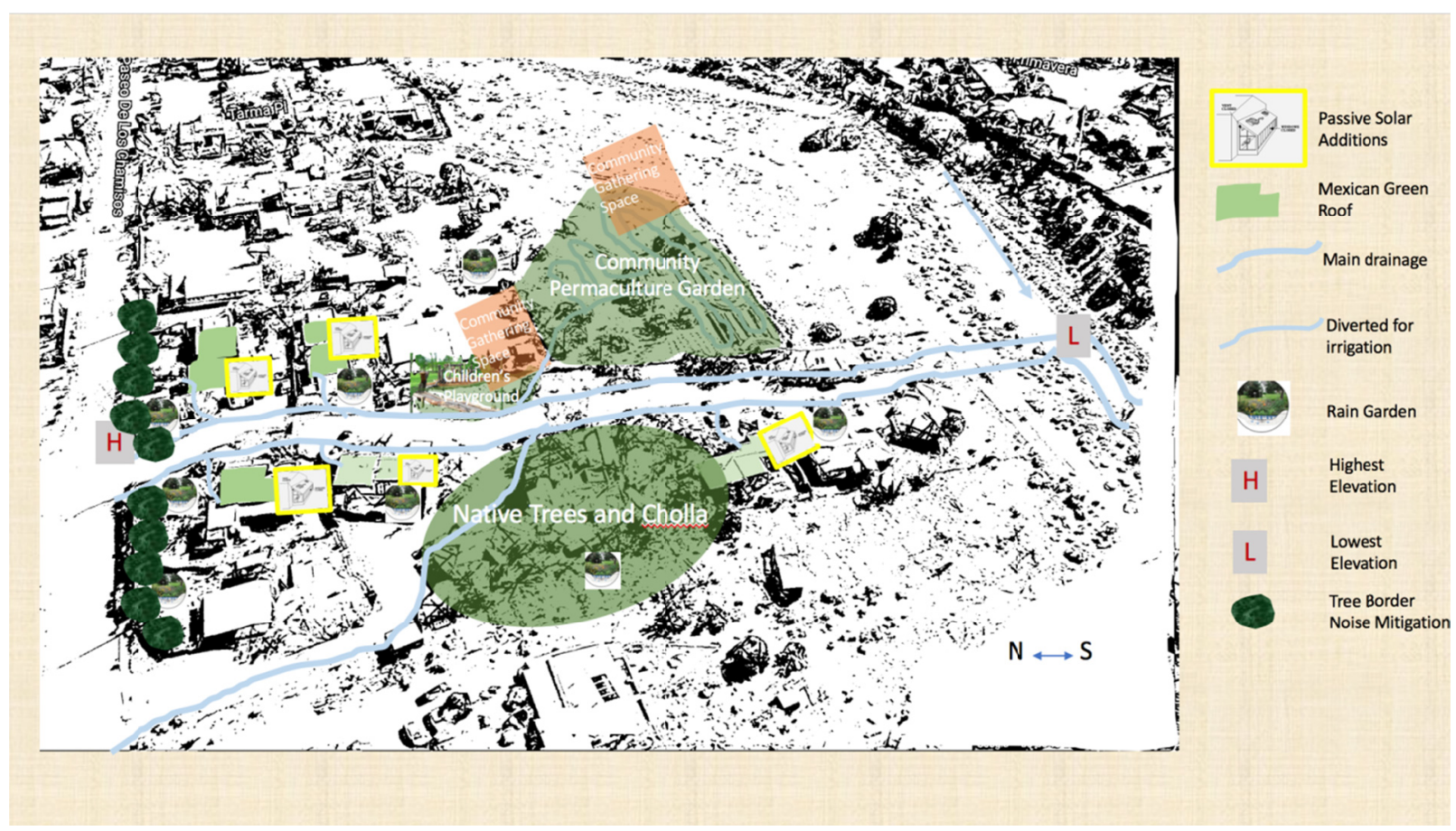


Figure 7. Original Ranch House and surrounding land of Rancho Siringo Neighborhood in Santa Fe, New Mexico. Retrofitting and Reconfiguration Plan for Sustainable, Participatory Community Pocket Neighborhood (2017)

As demonstrated in communities and cultures throughout the world, agriculture is a natural "knitter" in societies dating back to the very beginning of civilization and therefore, an excellent starting point in the forging of neighborhoods. The petals, or imperatives in the living building and living community challenge, though a commodified version of sustainable modeling, provide a map for all construction design as well as community planning direction. The focus of the living community challenge is upon populace well-being, community ties, beauty in surroundings, and sustainable living practices. The current highest standard of sustainable measurement, the living building and community challenges serve to disrupt the status quo and shift mindsets toward new possibilities and methods in construction and design (International Living Future Institute, 2017).

Shown above, Figure 7 provides the conceptual site plan for the transformation of an identified, historical neighborhood experiencing the challenges of urban sprawl in Santa Fe, New Mexico. Such locations identified throughout cities, require an overall site plan, addressing the main actions considered important and to be taken as a community. The first step is found in safeguarding equanimity of voice: a collection of opinions, needs and ideas, followed by the generation of solutions. Important questions include those which address social and economic needs. It is imperative to consider the behavioral and freedom of choice options that are available to all members of neighborhoods: Identifying what matters most to those involved as well as what is possible as far as policy is concerned. In the sample site plan shown above, the removal of walls and fences, return of a community farm, as well as rain gardens, water harvesting, attached greenhouses for solar gain and food security, a children's play area and establishment of community gathering spaces, has been created. The site plan offers a view that is only slightly different from that of the suburban sprawl currently surrounding the vicinity and yet within its design lay a plethora of connecting possibilities to greenspaces throughout the City and other neighborhoods. Particular attention is focused upon the need for water harvesting and recycling due to the high desert climate of the location, closeness to a major and vital arroyo drainage system, and the cultural value of the Santa Fe River. The continuation of incremental steps toward the additions shown in the structures and on the land, provide the gradual transformation toward a groups' active involvement in their environment and the ecosystems upon which they rely, meanwhile reducing carbon footprints and solidifying community relationships.

\section{Conclusion}

Through center focused planning and retrofitting built environments with ease of access to nature, incorporating the requirement of dependence and early contact with the immediately surrounding environments in the design of neighborhoods, the costs associated with mental health maintenance, as well as carbon footprints will be reduced, and the next generation of environmental stewards will emerge. Applying these findings in practical ways to small areas throughout urban centers empowers communities to set up their own best, sustainability solutions in partnership with each other; a strategic approach that is further realized through planning policy incentivizing innovation and community connection in this regard.

The tour through which the reader has been led offers a macro to micro journey into the possibilities for a more natural path than humankind has traversed in the past 100 years without the limiting of accessibility through commodification, hegemonic motivations of trademarking, divisive tactics and corporate credentialing. Fortunately, the ancestors of humanity and many remaining cultures possess a great deal of knowledge that is still available for application today. Science shows definitively that the brain is healthier on nature, that mental health is improved in green buildings, and that soil under the fingernails brings about a sense of calm and increases immune system functioning. It is almost too simplistic for those who are accustomed to the stressful chaos of urban-centered life, to believe. The implication in this finding is that any introduction of more nature, exposure to pleasant scenery, early and direct contact with nature, in a habitat, a school, a hospital, supports place attachment, stewardship and therefore, emotional well-being.

The data shows the same strong connection to mental health and resiliency in the social realm: People need people. Human beings need to feel connected to others in a way that is meaningful. Culture and how cities and neighborhoods are configured will support or tear down this need. However, the culture of a nature-dependent community: A nature-educated community in shared relationship with the center of their home, valueing their surroundings, gardening, collecting water, planting trees, caring for the preservation and beauty of the land, water, and air - together as a community, provides an opportunity for a mutual common bond with nature and the creative forces upon which humans rely for their existence. 
Equally important are the systems which foster the culture within a community: Federal and local policy in alignment with the vision of creating a culture of nature dependent residents provides support for the connected human story as well as the essential benefits of resiliency required of all communities in the face of climate change-adaptation for survival and thriving together, in cooperative and participatory alliances which date to the beginning of time- it is simple. The ideals of sustainable design are too often packaged in corporate labels, and criteria meant to motivate through the economy, yet that same economy often results in more damage to the environment. Everyday people wield the most power in affecting genuine change in their communities. Those who have come before, developing efficient, sustainable and intimate relationships with place and nature prove this. Those who continue in the sustainable day-to-day practice of indigenous wisdom demonstrate the logical potential of maintaining life preserving values and skills of relationship to earth.

In focus of potential horizons, it is proposed that a return in approach that mirrors the core concepts of our ancestors methodology, before industrialization was adopted begin; an approach informed by collaborative systems yet open to cultural and ecologically relevant participatory innovation. These systems emphasize community efforts in order to create the built environments for children to live and play that are inseparable from nature. For a healthy and resilient future, efforts should be paid to design built environments and cities in such a way that link humans with each other and our planet in collaborative, interdependent, interactive relationship, and intention. The way of nature - the foremost "best of" model, unpackaged, and within which humans are inextricably, and wondrously a part.

\section{References}

Anzilotti, E. (2016, Mar 7). City Lab; Could Urban Farms Be the Preschools of the Future? Retrieved February 2 , 2017 , from http://www.citylab.com/navigator/2016/03/could-urban-farms-be-the-preschools-of-the-future/472548/?utm _source=modernfarmer

Aut-Aut. (2017). Nursery Fields Forever. Retrieved from: http://www.aut--aut.it/nursery-fields-forever/

Beam, J. (2017). MRP: Mental Health and Resiliency: Designing Participatory Nature Dependent Environments and Collaborative Community Cultures for a Sustainable Future. University of Florida, Gainesville, FL.

Birnbaum, J., \& Fox, L. (2017, July 23). The Sustainable [R] evolution; Documenting community based solutions around the globe. Retrieved July 23, 2017, from http://www.cultureofpermaculture.org/blog/2007/05/taos-new-mexico-greater-world-earthship-community/

Bratman, G. N., Hamilton, J. P., Hahn, K. S., Daily, G. C., \& Gross, J. J. (2015). Nature experience reduces rumination and subgenual prefrontal cortex activation. 2015/07/14 Proceedings of the National Academy of Sciences N1 - 10.1073/pnas.1510459112. Vol112 Issue - 28. Retrieved from http://www.pnas.org/content/112/28/8567.abstract

Bretherton, I. (1992). The Origins of Attachment Theory: John Bowlby and Mary Ainsworth. Developmental $\begin{array}{lllll}\text { Psychology 28, 759-775. } & \text { Retrieved } & \text { from }\end{array}$ http://www.psychology.sunysb.edu/attachment/online/inge_origins.pdf

Buckminster Fuller Institute. (2017, January 28). About Fuller. Retrieved January 28, 2017, from https://www.bfi.org/about-fuller/biography/introduction-buckminster-fuller

Buettner, D. (2010). The Blue Zones: Lessons for living longer from the people who have lived the longest. Washington D.C. National Geographic Society.

Cabello, J. J. et al. (2012). Environ Dev Sustain, 14, 573. Retrieved from https://doi.org/10.1007/s10668-012-9338-8

Central Intelligence Agency. (2017). Costa Rica. Retrieved from https://www.cia.gov/library/publications/the-world-factbook/geos/cs.html

Chanuki Illushka Seresinhe. (2016). UD/MH; Journal of Urban Design and Mental Health. Retrieved July 22, 2017, from http://www.urbandesignmentalhealth.com/journal1-beautifulplacesandwellbeing.html

Chiarotto, L. (2011). Natural Curiosity, A Resource for Teachers: Building children's understanding of the world through environmental inquiry. Oshawa, ON. Retrieved from http://www.naturalcuriosity.ca/pdf/NaturalCuriosityManual.pdf

City Data. (2017, July 22). City Data: Health and Nutrition of Taos Pueblo. Retrieved July 22, 2017, from http://www.city-data.com/health-nutrition/Taos-Pueblo-New-Mexico.html 
Common Place. (2017). Retrieved from http://www.common-place-archives.org/vol-03/no-04/santa-fe/

Disruptive Investor. (2016, April 23). DI: Focus Norway Edition: Infographic On Norway's Oil And Gas Sector. Retrieved June 30, 2017, from http://www.disruptiveinvestor.com/index.php/economy-global/focus-norway-edition-infographic-on-norwa y-s-oil-and-gas-sector

Dyck, J. (2002). Montessori Life. The Built Environment's Effect on Learning: Applying Current Research. Retrieved from http://www.taparch.com/pdf/montessor2002.pdf

Earthship Architecture. Parkin Pinterest. (2017). Retrieved from https://www.pinterest.com/parkin0597/earthship-architecture/

Earthship Biotecture; Design Principles. (2017, July 22). Retrieved July 22, 2017, from http://earthship.com/design-principles

Ecovillage Ithaca. (2017). Living Greener. Retrieved January 27, 2017, from http://ecovillageithaca.org/live/living-greener/

Environmental Protection Agency. (2017, July 22). Open Practices: Sustainable Communities \& Behaviour Change. Retrieved July 22, 2017, from http://www.openpractices.net/sustainable-communities/

Frumpkin, H. (2003). Healthy Places: Exploring the evidence. American Journal of Public Health, 93(9), 1451-1456. Retrieved from https://www.ncbi.nlm.nih.gov/pmc/articles/PMC1447992/

Funes Monzote, F. (2008). Farming like we're here to stay: The mixed farming alternative for Cuba. Tesis doctoral, Wageningen University.

Google Maps. (2017). 2215 Rancho Siringo Rd. Image adapted by Jacqueline Beam. Retrieved from https://www.google.com/maps/place/2215+Rancho+Siringo+Rd,+Santa+Fe,+NM+87505/@35.6460716,-1 $05.9794412,321 \mathrm{~m} / \mathrm{data}=! 3 \mathrm{~m} 1 ! 1 \mathrm{e} 3 ! 4 \mathrm{~m} 5 ! 3 \mathrm{~m} 4 ! 1 \mathrm{~s} 0 \times 87185 \mathrm{a} 73 \mathrm{ceb} 7188 \mathrm{~b}: 0 x a e c a a 0 b 1 \mathrm{~cd} 64 \mathrm{~b} 212 ! 8 \mathrm{~m} 2 ! 3 \mathrm{~d} 35.646$ $0673 ! 4 d-105.9783481$

Harvard T.H. Chan. (2015). School of Public Health. Retrieved from https://www.hsph.harvard.edu/news/press-releases/green-office-environments-linked-with-higher-cognitivefunction-scores/

Helliwell, J., Layard, R., \& Sachs, J. (2017). World Happiness Report 2017. New York: Sustainable Development Solutions Network.

Herzog, L. (2006). Return to the Center: Culture, Public Space, and City Building in a Global Era. Austin, TX. University of Texas Press.

Hoover, E. (2014, June 26). From Garden Warriors to Good Seeds: Indigenizing the Local Food Movement. Retrieved May 5, 2017, from www.gardenwarriorsgoodseeds.com

Howarth, R. (2012). Center for Humans \& Nature: Sustainability, Well-being, and Economic Growth. Volume 5 number $2 . \quad$ Retrieved from https://www.humansandnature.org/sustainability-well-being-and-economic-growth

International Living Future Institute. (2017). Living Community Summary Matrix. Retrieved from https://living-future.org/lcc/basics/\#overview

Kahn, P. J. (1997). Developmental Psychology and the Biophilia Hypothesis: Children's Affiliation with Nature. Developmental Review, 17, 1-61. Retrieved from http://faculty.washington.edu/pkahn/articles/Developmental_Psychology_Biophilia_Hypothesis.pdf

Kurzweilai; Accelerating Intelligence. (2017). Retrieved June 10, 2017, from http://www.kurzweilai.net/images/rumination-to-sgPFC.jpg

Lejuwaan, J. (2012, Oct 3). Earthship Biotecture: 10 Reasons Why Earthships Are F!\#\%ing Awesome. Retrieved Jul 22, 2017, from http://earthship.com/blogs/2012/10/10-reasons-why-earthships-are-fing-awesome/

Leyes. (1997). Constitucion de la Republica de Cuba (reformada) [Internet]. La Habana, Cuba [cited February 15, 2011]. Retrieved from http://www.cuba.cu/gobierno/cuba.htm

Louv, R. (2005). Last Child in the Woods; Saving our children from nature-deficit disorder. New York, New York. Algoquin Books of Chapel Hill.

Mehta, N. (2011). Mind-body Dualism: A critique from a Health Perspective. Mens Sana Monographs, 9(1), 202209. http://doi.org/10.4103/0973-1229.77436 
Morris, H. (2016) The Babushkas of Chernobyl. Retrieved February 24, 2017, from http://thebabushkasofchernobyl.com/contact

Nambe Pueblo (Native Americans of the Southwest). (2017). Retrieved Jul 23, 2017, from http://what-when-how.com/native-americans/nambe-pueblo-native-americans-of-the-southwest/

OECD Data: Better Policies for Better LIves. (2017, July 15). Retrieved July 22, 2017, from https://data.oecd.org/air/air-and-ghg-emissions.htm

Photo by Kirsten Jacobsen. (2017). Earthship Biotecture. Retrieved from https://www.washingtonpost.com/lifestyle/travel/at-this-earthship-community-in-new-mexico-renters-can-g ive-sustainable-living-a-try/2016/09/27/3f41b3ac-6e23-11e6-9705-23e51a2f424d_story.html?utm_term=.74 c359fa5d95

Psychologist World. (2017, January 27). Attachment Theory. Retrieved January 27, 2017, from https://www.psychologistworld.com/developmental/attachment-theory.php

Robert Wood Johnson Foundation. (2008, September). Commission on Health; Where We Live Matters for our Health; Neighborhoods and Health. Retrieved July 15, 2017, from http://www.commissiononhealth.org/PDF/888f4a18-eb90-45be-a2f8-159e84a55a4c/Issue\%20Brief\%203\% 20Sept $\% 2008 \% 20-\% 20$ Neighborhoods\%20and\%20Health.pdf

Rosero-Bixby, L., Dow, W. H., \& Rehkopf, D. H. (2013). The Nicoya region of Costa Rica: a high longevity island for elderly males. Vienna Yearbook of Population Research / Vienna Institute of Demography, Austrian Academy of Sciences, 11, 109-136.

Schmutz, U., Lennartsson, M., Williams, S., Devereaux, M., \& Davies, G. (2014). The benefits of gardening and food growing for health and wellbeing.

Seresinhe, Preis \& Moat. (2015). Quantifying the Impact of Scenic Environments on Health 2015/11/25/online; vol. 5, 16899. http://dx.doi.org/10.1038/srep16899

Statistics Norway. (2017, June 30). Statistics Norway. Retrieved July 1, 2017, from https://www.ssb.no/en/befolkning/nokkeltall/population

Stiftung, V. B. (2013). Winning Strategies for a Sustainable Future. Retrieved January 5, 2017, from https://www.bertelsmann-stiftung.de/fileadmin/files/Projekte/31_Nachhaltigkeitsstrategien/Case-Study-Cos ta-Rica_Reinhard-Mohn-Prize-2013_20131016.pdf

Striker, P. (2010). Bringing social justice back in: Cuba revitalises sustainable development. Local Environment, 15(2), 185-197.

Trulia: Lot 41 Earthship Way Greater World Community. (2017, July 22). Retrieved July 22, 2017, from https://www.trulia.com/property/3268792905-Lot-41-Earthship-Way-Greater-World-Community-Taos-NM $-87571$

Unesco World Heritage LIst. (2017, July 22). Unesco World Heritage List; Taos Pueblo. Retrieved July 22, 2017, from www.whc.unesco.org: http://whc.unesco.org/en/list/492

Unesco World Heritage LIst. (2017, July 22). Unesco World Heritage List; Taos Pueblo. Retrieved July 22, 2017, from http://whc.unesco.org/en/list/492

Wilson, E. (1984). Biophilia; The human bond with other species. Cambridge, Massachusetts, and London, England. Harvard University Press.

Wiskind, A. (2007). Cuba: sustainability pioneer? [Internet].World Watch, July-August, 2007. Aptos. CA., USA [cited February 15, 2011]. Retrieved from http://findarticles.com/p/articles/mi_hb6376/is_4_20/ai_n29357385/

Worldwatch Institute. (2017, July 22). Worldwatch; Vision for a Sustainable World. Retrieved July 22, 2017, from http://www.worldwatch.org/node/810

\section{Copyrights}

Copyright for this article is retained by the author(s), with first publication rights granted to the journal.

This is an open-access article distributed under the terms and conditions of the Creative Commons Attribution license (http://creativecommons.org/licenses/by/4.0/). 